\title{
Looking for Trouble: A Search for Developmental Defects of the Hypothalamus
}

\author{
Aurore Caqueret Chun Yang Sabine Duplan Francine Boucher \\ Jacques L. Michaud \\ Research Center, Hôpital Sainte-Justine, Montréal, Canada
}

\section{Key Words}

Hypothalamus, developmental defects - Transcription

factor $\cdot$ Imprinting $\cdot$ Energy balance

\begin{abstract}
The hypothalamus is a critical integrator of several homeostatic processes that are required for the survival of vertebrates. Disruption of the development of the hypothalamus thus has the potential of perturbing important physiological processes with lifelong consequences. We review current knowledge about how cell types are specified and circuits are formed within the developing hypothalamus. We emphasize the potential clinical impact of the perturbations of these pathways using the regulation of energy balance as a model. We predict that disruption of hypothalamic development is a common, previously unsuspected cause of disorders of homeostatic processes such as obesity and high blood pressure.
\end{abstract}

Copyright @ 2005 S. Karger AG, Basel

\section{Introduction}

The hypothalamus is an evolutionary ancient integrator of homeostasis that regulates basic processes such as food and water intake, energy expenditure, the response to stress, blood pressure, and reproduction. Structurally, the hypothalamus is composed of a dozen small nuclei interspaced between less defined regions. A great body of work involving physiological and genetic studies has assigned specific functions to each of these nuclei and regions (see summary in fig. 1). In contrast, relatively little attention has been paid to how the different components of the hypothalamus are specified and connected. Understanding the development of the hypothalamus has the potential of shedding light on frequent pathological processes that can manifest even late in life. An immediate illustration of this principle is provided by classical work done on the development of gonadotropin-releasing hormone (GnRH) neurons and its disruption in some conditions affecting puberty [1]. Here, we review basic knowledge about other aspects of hypothalamic development focusing on how cell types are specified and axonal connections are established. The potential clinical impact of the perturbations of these pathways is illustrated using the regulation of energy balance as a model.

\section{Patterning of the Hypothalamus by Extrinsic Signals}

Axial signals provided by the mesendoderm underlying the rostral neural plate are required to divide the primordial single eye field into two eyes [2]. Failure of this process causes holoprosencephaly, the most frequent

\section{KARGER \\ Fax +4161306 1234 E-Mail karger@karger.ch} www.karger.com
(C) 2005 S. Karger AG, Basel 0301-0163/05/0645-0222\$22.00/0

Accessible online at: www.karger.com/hre
Dr. Jacques L. Michaud

Research Center, Hôpital Sainte-Justine

3175 Côte Sainte-Catherine, Montréal, Qué., H3T 1 C5 (Canada)

Tel. +1 514345 4727, Fax +1 5143454766

E-Mail jacques.michaud@recherche-ste-justine.qc.ca 
Fig. 1. Structural and functional relationship between hypothalamic nuclei. The paraventricular (PVN) and supraoptic nuclei contain magnocellular neurons (in red), producing either OT or AVP, that project to the posterior pituitary. The PVN also contains parvocellular neurons (in blue) that project to the medial eminence (ME) where they secrete a number of factors, including TRH and $\mathrm{CRH}$, that are taken up by the small vasculature of the ME and transported to the anterior pituitary. These factors modulate secretion of anterior pituitary hormones. A second population of parvocellular neurons project to preganglionic neurons of the autonomic nervous system. The ARC, which is located just dorsal to the ME, projects axons to the PVN, the dorsal median nucleus (DMN) and the lateral hypothalamic area (LHA), whereas the ventromedial nucleus (VMN) projects to several intra- and extrahypothalamic sites. The adiposity signal leptin reduces food intake at least in part by acting in the ARC. ARC neurons expressing Npy/Agrp and Cart/Msh project to the PVN $[65,66]$. Electrophysiological studies have shown that individual neurons within the PVN are capable of detection and integration of the NPY and MSH signals [67]. Leptin decreases the expression of Npy and Agrp transcripts in medial cells and increases the expression of Cart and Msh transcripts in lateral cells of the ARC [65]. Genetic and physiological studies indicate that both NPY and AgRP increase food intake and decrease energy expenditure [68-70], whereas CART and MSH, which is derived from POMC, have the opposite effects [71, 72]. These changes of expression are expected to generate a similar physiological response as that of leptin - decrease of food intake and increase of energy expenditure.

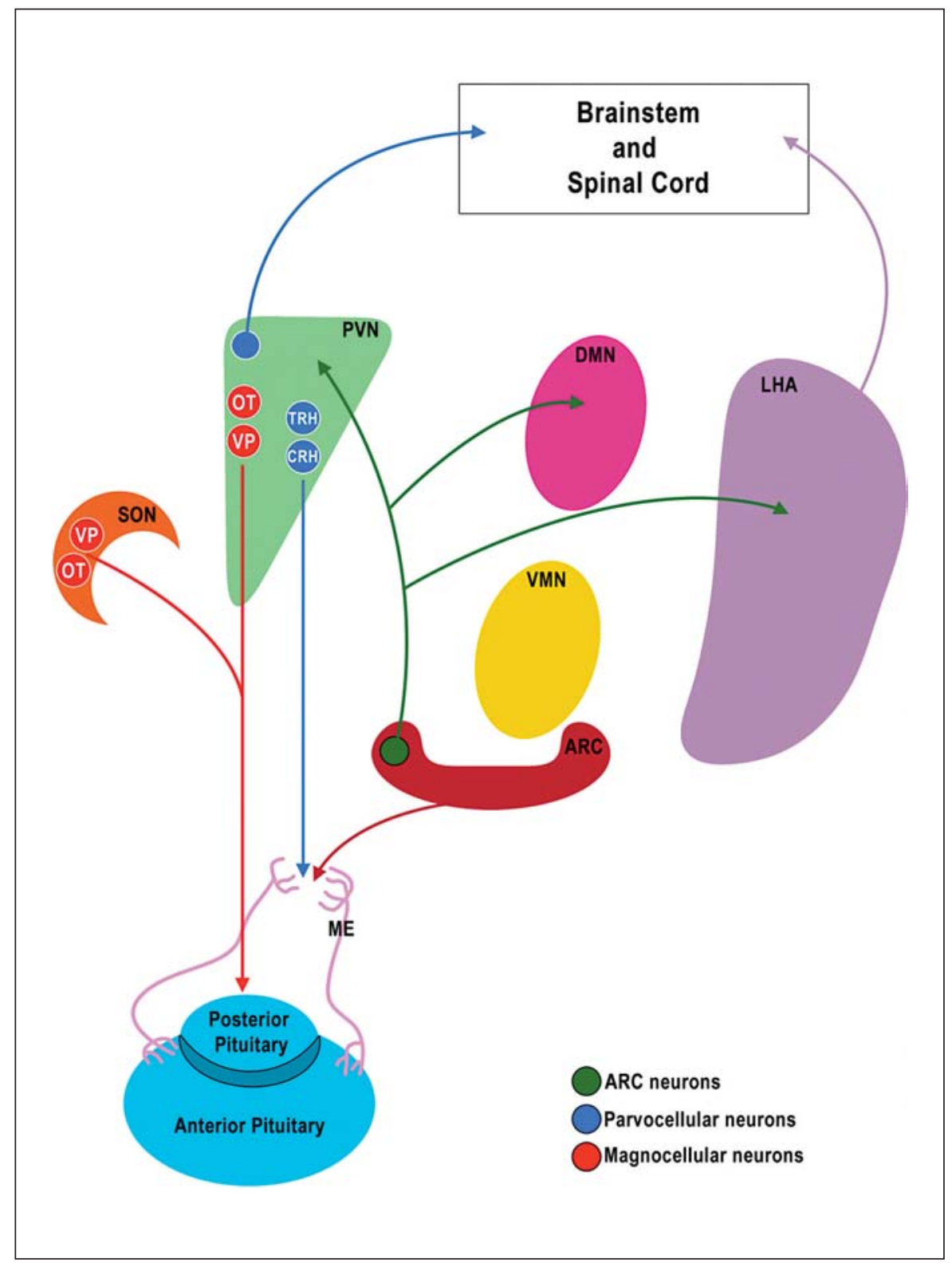

brain malformation [3]. Because these axial signals are also required to induce development of the hypothalamus between the two eyes, it is not surprising that it is either missing or lacking in structures in holoprosencephalic brains. In fact, endocrine deficiencies, caused by hypothalamic and/or pituitary dysfunction, can be the only clinical problem in milder forms of holoprosencephaly. Currently, mutations in eight genes have been shown to cause holoprosencephaly in humans [4]. Three of these genes (SHH, PTC1, GLI2) encode members of the Sonic Hedgehog signaling pathway, whereas two others have the po- tential of interacting with this pathway (SIX3, ZIC2). The other genes (TDGF1, FAST1, TGIF) appear to interact with the Nodal/TGF- $\beta$ signaling pathway. Consistent with the pathophysiology of holoprosencephaly, SHH and Nodal are axial signals that are required for hypothalamus induction (reviewed in [2]). Interestingly, these signals also appear to function for subsequent regionalization of the hypothalamus. Although the severe midline defect observed in Shh- and Nodal-mutant mice precluded investigation of such a role, recent studies in fish suggest that hedgehog and Nodal signaling pattern the prospective hy- 
pothalamus into distinct domains [5] (reviewed in [2]). Experiments performed in fish also indicate that inhibition of $W n t$ signaling in the neural plate is required, likewise, for the specification of the hypothalamus anlage and also for its regionalization [6]. The identification of signals that regionalize the hypothalamus represents a critical step towards the elucidation of mechanisms underlying its organization into a set of small nuclei.

Another source of organizing signals for the hypothalamus is the anlage of the anterior pituitary. Coculture experiments have shown that the development of ACTH/ MSH cells of the prospective arcuate nucleus (ARC), located in the ventromedial hypothalamus, is enhanced by a signal provided by the Rathke's pouch [7]. Also, Hermesz et al. [8] have characterized a Hesx 1 regulatory element that directs the expression of a reporter transgene in the ventral hypothalamus of mice, in a region that lies in direct contact with Rathke's pouch [8]. In tissue recombination experiments, the pouch can induce expression of the transgene in the neurectoderm isolated from other sites of the developing forebrain, suggesting that the Hesx 1 element responds to a signal emanating from the pouch. It is not yet clear whether the signal produced by the pouch that enhance the development of ACTH/MSH cells is the same as that required for the transgene expression in the ventral hypothalamus. Based on these observations, a prediction can be made that disruption of the development of the pouch might affect the development of the ventral hypothalamus.

\section{Trancriptional Control of Cell-Type Specification in the Hypothalamus}

Differentiation of neurons typically involves cascades of transcription factors that progressively define their phenotypes. Such cascades have been characterized in cells that populate hypothalamic nuclei.

\section{Paraventricular and Supraoptic Nuclei}

The homeobox-containing transcription factor OTP and the heterodimeric complex formed by the bHLHPAS transcription factors SIM1 and ARNT2 are required for the development of (1) virtually all neurons of the paraventricular $(\mathrm{PVN})$ and supraoptic $(\mathrm{SON})$ nuclei, including those identifiable by the production of thyrotropin-releasing hormone $(\mathrm{TRH})$, corticotropin-releasing hormone (CRH), oxytocin (OT), and arginine vasopressin (AVP); (2) somatostatin (SS) parvocellular neurons of the anterior periventricular nucleus, which is contiguous to the PVN; and (3) other populations of hypothalamic TRH neurons found in the lateral areas and preoptic region [9-14]. SIM1:ARNT2 and OTP function along parallel pathways to control multiple aspects of the development of these cell types, including the proliferation of their progenitors, differentiation, and migration [9-14; Caqueret et al., unpubl. data].

SIM1:ARNT2 and OTP act upstream to maintain the expression of Brn2, a POU domain transcription factor, and $\operatorname{Sim} 2$, a close homolog of Sim1, which, in turn, control the differentiation of distinct populations of hypothalamic neurons (fig. 2). Brn2 is required for the differentiation of CRH, OT, and AVP neurons of the PVN/SON $[15,16]$. The fact that Brn2 regulates the activity of the $\mathrm{Crh}$ promoter in vitro suggests that it acts at the final stage of differentiation [15]. In contrast, these PVN populations of OT-, AVP-, and CRH-expressing cells are not affected in Sim2 $2^{-/-}$embryos but TRH cells as well as the SS cells of the anterior periventricular nucleus are decreased by 43 and $83 \%$, respectively, in these embryos [17]. The interplay between $\operatorname{Sim} 1$ and $\operatorname{Sim} 2$ is complex. $\operatorname{Sim} 1$ acts upstream to maintain $\operatorname{Sim} 2$ expression, but it can also compensate, albeit ineffectively, for loss of Sim2. It is unclear whether TRH and SS cells that require Sim2 for their development and those that do not require Sim 2 have different properties or function.

Brn 2 and Sim2 are thus required for the differentiation of distinct cell types. The domain of Brn2 expression is located anteriorly compared to that of $\operatorname{Sim} 2$, correlating with the spatial distribution of the cell types in which they function [17]. These observations provide novel insight into the emergence of the neuronal topography of the anterior hypothalamus.

\section{Arcuate Nucleus}

The ARC is composed of distinct cell types whose identity and spatial distribution have not yet been fully resolved [18]. Early on during development, signals produced by the axial mesendoderm induce the expression of the homeobox-containing transcription factor NKX2.1 in the overlying presumptive hypothalamus [19-21]. In turn, $N k \times 2.1$ functions to specify the anlage of the ventral hypothalamus that will give rise to arcuate and the ventromedial nuclei $[19,22]$. A set of homeobox-containing transcription factors has been shown to function downstream to specify some of the cell types populating the ARC (fig. 3). For instance, Gshl is required for Ghrh (growth-hormone-releasing hormone) expression in the $\mathrm{ARC}$, whereas in vitro studies indicate that it can regulate Ghrh expression directly by interacting with its promoter 


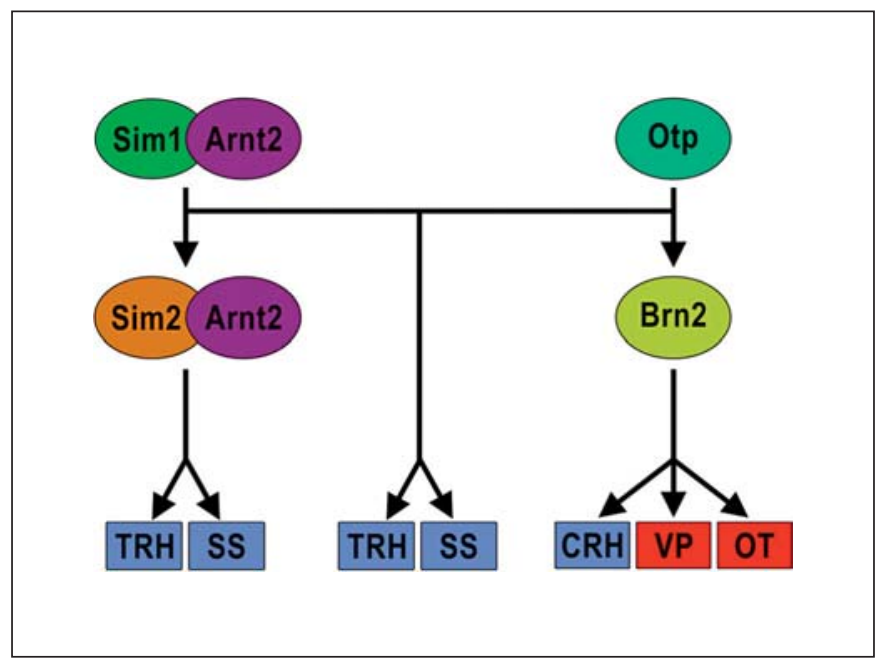

Fig. 2. Transcriptional regulation of anterior hypothalamic development. SIM1:ARNT2 and OTP function in parallel to control the development of virtually all neurons of the PVN/SON, of TRHproducing neurons of the preoptic region and of SS-producing neurons of the anterior periventricular nucleus, which is located ventrally contiguous to the PVN. These two complexes are required to maintain Brn2 expression, which, in turn, directs the development of CRH-, OT- and AVP-producing neurons of the PVN and SON. SIM1:ARNT2 and OTP also act upstream of SIM2 for the development of subsets of TRH cells located in the PVN and preoptic region and of SS cells found in the anterior periventricular nucleus.

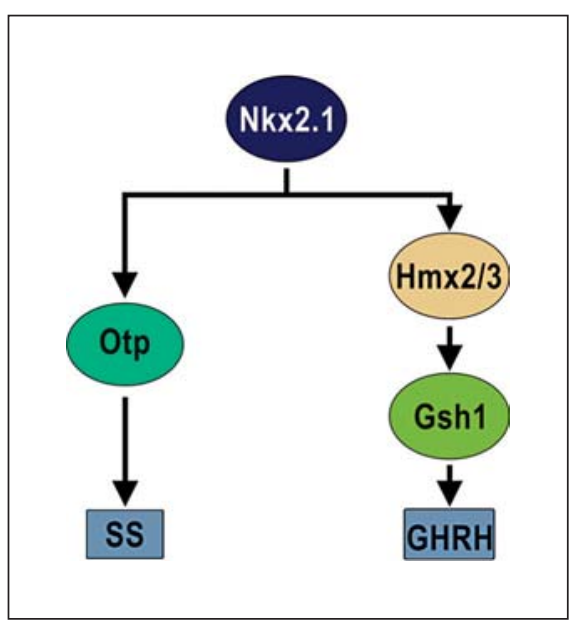

Fig. 3. Transcriptional regulation of arcuate nucleus development. $N k x 2.1$ functions early during development to specify the ventral anlage of the caudal hypothalamus, which includes the ARC. Hmx2 and $H m x 3$ together act upstream of Gsh 1 for the expression of $G h R H$, whereas Otp is required for $S s$ expression in the ARC.
[23]. $H m \times 2$ and $H m \times 3$ together are also required for $G h r h$ expression, at least in part, by maintaining Gsh1 expression [24]. Otp affects the development of another cell type in the ARC identifiable by the production of SS $[13,14]$. As mentioned above, Otp also affects $S s$ expression in other regions of the diencephalon, including the anterior periventricular nucleus and zona incerta. It is likely that Gsh $1, H m \times 2 / H m \times 3$, and Otp not only function to regulate the expression of Ghrh and Ss, but also have a more global impact on the differentiation of the cells in which they are expressed.

\section{Ventromedial Nucleus}

Steroidogenic factor 1 (SF1), an orphan member of the nuclear receptor family, is required for the development of several endocrine systems. Sf1-homozygous mice lack gonads and adrenals and have impaired function of pituitary gonadotropes $[25,26]$. The only site of $S f 1$ expression in the brain is the ventromedial nucleus (VMN). The $\mathrm{VMN}$ of $S \mathrm{I}^{-/-}$embryos, but not of heterozygotes, shows a complex phenotype [25, 27-31]. VMN-mutant neurons are generated during development in appropriate number but their spatial distribution is altered with more neurons located medially and dorsally $[30,31]$. The fact that the axonal projections originating from the VMN are absent in these mutants suggest that $S f 1$ not only affects migration of neurons but also their differentiation.

\section{Physiological Relevance of Transcriptional Regulators of Hypothalamus Development}

Loss of all known regulators of PVN/SON development - Sim1, Arnt2, Otp, Brn2 and Sim2 - in mice result in perinatal lethality. The severe PVN/SON defects found in mutants, such as $\operatorname{Sim} 1$ or Otp, might underlie their lethality. In contrast, Sim $1^{+/-}$mice survive and develop early onset obesity, with increased linear growth, hyperinsulinemia, and hyperleptinemia. These mice are hyperphagic, even before they show increased weight gain [32, 33]. A balanced translocation interrupting SIMI was found in a child with a similar phenotype [34]. Like $\mathrm{Sim}^{+/-}$mice, this child had early onset obesity, increased linear growth, and a voracious appetite, suggestive of hyperphagia. Mouse models suggest that SIMI haploinsufficiency is responsible for the obesity in this child. The description of morbid obesity in children with chromosomal deletions in the $6 \mathrm{q} 16$ region, which contains SIM1, further strengthens this conclusion [35-37]. Interestingly, a genome-wide search for childhood obesity traits has 
shown significant linkage on chromosome 6q22-q23, near the SIM1 locus [38]. The mechanisms underlying the hyperphagia associated with $\operatorname{Sim} 1$ haploinsufficiency are still under investigation. One possibility is that dysfunction of the PVN causes this hyperphagia (fig. 1). This dysfunction could be of developmental origin. Indeed, the PVN of $\mathrm{Siml}^{+/-}$mice is hypocellular, containing $24 \%$ fewer cells [32]. However, since $\operatorname{Sim} 1$ and its dimerizing partner Arnt2 are expressed continuously in the postnatal PVN, the possibility that Sim 1 controls food intake physiologically is not excluded.

Brn2 is also expressed in the postnatal PVN/SON. The regulation of $\mathrm{Crh}$ expression by $\mathrm{Brn} 2$ in cultured cells and the fact that $A v p$ and $O t$ mRNA levels are reduced in Brn2-heterozygous mice raise the possibility that Brn2 participates in physiological processes by controlling the expression of these effectors dynamically $[15,16]$. However, overexpression of $\mathrm{Brn} 2$ in the PVN using adenoviral vectors does not affect expression levels of $A v p$ and $C r h$ [39]. Also, the expression of $\mathrm{Brn} 2$ is not changed in a stress model associated with increased production of CRH [40]. Nevertheless, the possibility that $\mathrm{Brn} 2$ regulates $\mathrm{Crh}$ expression in the postnatal PVN/SON in response to specific stimuli needs further exploration. For instance, it has been shown that Brn 2 overexpression is not sufficient per se to induce $C R H$ expression but is required for retinoicacid-induced $C R H$ expression in a neuroblastoma cell line [41].

$S f 1^{-1-}$ mice can be rescued from adrenal insufficiency at birth by corticosterone replacement or adrenal transplantation [29]. These rescued mice show increased weight gain by 8 weeks of age and eventually weighed almost twice as much as wild-type controls. $S f 1^{-1-}$ mice are not hyperphagic but show decreased locomotor activity. This model will be useful for the dissection of the role of $\mathrm{VMN}$ in the regulation of energy balance.

\section{Establishment of Circuitries}

During development, attractive and repulsive cues guide axons towards their targets. Very little, however, is known about the molecules that guide hypothalamic axons. Recent studies have shed some light on how one set of axons, those originating from GnRH neurons, reach their target. GnRH neurons originate from the olfactory epithelium, migrate following olfactory/vomeronasal axons and settle in a continuum from the olfactory bulbs to the hypothalamus. Specification and migration of GnRH neurons has been reviewed elsewhere and will not be fur- ther discussed here [1]. The majority of GnRH neurons projects to the median eminence (ME). Explant and transplantation studies indicate that the ME produces a diffusible attractive signal for GnRH axons [42]. A prototypical guidance molecule is netrin-1, a secreted protein that attracts axons by interacting with its receptor DCC. Netrin-1 is produced in medial areas flanking the third ventricle in which GnRH axons progress as well as in the prospective ME, whereas GnRH neurons express DCC [43]. Loss of netrin-1 or DCC reduces dramatically the number of GnRH axons that reach the ME, suggesting that netrin-1 is a major cue for the guidance of these axons towards their target [43]. In contrast, CRH and AVP axons grow normally into the ME and posterior pituitary, respectively, of these mutants. Previous studies have established that dopaminergic, GHRH, and SS neurons restrict their projections to certain subregions of the ME (reviewed in [44]). Altogether, these observations suggest the existence of a complex network of cues produced by distinct domains of the prospective ME that each attracts different sets of hypothalamic axons.

Whereas axon projections to the ME and infundibulum are established by the time of birth in rodents, recent studies indicate that this is not the case for all hypothalamic projections. Bouret et al. [45] have found that ARC projections to the PVN, lateral hypothalamic area, and the dorsal medial nucleus develop during the first 2 weeks of postnatal life in mice. These ARC projections are critical mediators of the action of leptin on food intake. The fact that these projections are not yet completely developed at this stage of life might explain the insensitivity of the neonatal hypothalamus to the massive surge of leptin levels observed during the first week of life in rodents [46]. Interestingly, Bouret et al. [47] found that leptin actually acts as a trophic signal that stimulates ARC axon outgrowth. More specifically, the density of ARC projections to the PVN, lateral hypothalamic area, and dorsal medial nucleus is decreased in leptin-deficient mice during the first 2 weeks of life, before weaning, and remains so in adulthood. Administration of leptin during the first 2 weeks, but not later in life, increases the number of ARC projections in leptin-deficient mice, which results in decreased food intake in the long term. Obesity secondary to leptin deficiency thus appears to involve a developmental component.

Interspecies comparisons of various features of neural development indicate that the brain of newborn mice is immature, corresponding to that of human fetuses at the beginning of the third trimester of pregnancy [48-50]. From a clinical point of view, factors that modulate levels 
of leptin in human fetuses or premature babies would thus be predicted to affect the development of ARC projections, with the potential of having long-lasting effect on energy balance. Alternatively, the development of these ARC projections after birth could represent a conserved feature of mammalian development, also present in humans, that defines a phase during which food intake would not be subjected to the same regulatory circuitries than later on, possibly reflecting the need to maximize food intake in the immediate postnatal period.

Projections of parvocellular OT neurons of the PVN to the dorsal vagal complex, a group of brainstem nuclei that comprises the dorsal motor nucleus of the vagus and the nucleus of the solitary tract, also increases during the first 2 weeks of postnatal life in rodents [51]. These axons have also been shown to mediate in part the effect of leptin on food intake [52]. An interesting possibility will be that the development of these projections is also stimulated by leptin during the first weeks of life. A functional correlate of the immaturity of this circuit has been proposed by Rinaman [51]. There is good evidence that OTcontaining projections from the PVN to the dorsal vagal complex are required for the anorexic response that accompanies dehydration [53]. Interestingly, this response does not emerge until after the first 2 weeks of postnatal development, possibly because of the lack of OT projections [51].

\section{Imprinting and Hypothalamic Development}

Analysis of chimeric embryos and mice containing normal and uniparental cells have shown that parthenogenetic (complete maternal disomy) and androgenetic (complete paternal disomy) cells contribute to complementary regions of the brain $[54,55]$. Although at 10 days of embryonic development, androgenetic cells appear widely distributed in the brain of chimeras, they subsequently become restricted to the hypothalamus. Conversely, parthogenetic cells are progressively excluded from the hypothalamus during development of chimeric brains, while they are found abundantly in the cortex. The stage during which these complementary distributions of uniparental cells are established coincides with the proliferation and differentiation of hypothalamic neural cells. This observation suggests that paternal expression of some genes is required for development of the hypothalamus.

Interestingly, at least two genes with monoallelic expression from the paternal allele, $P e g 3$ and $N d n$, might be required for the development of the hypothalamus. Peg3 is a critical regulator of several apoptotic pathways. Loss of the paternal copy of $P e g 3$ in mice causes a decrease of activation of the sympathetic nervous system, presumably via the hypothalamus, that is associated with lower core body temperature and metabolic activity as well as with an increase of white and brown adipose tissue [56]. $P e g 3$ is expressed at high levels during the development of several regions of the hypothalamus that regulate energy balance. It is thus tempting to speculate that the loss of Peg3 disrupts normal hypothalamic development through its role in apoptotic pathways, leading to a cascade of energy balance dysfunctions.

$N D N$ (encoding necdin) and MAGEL2 are two of four protein-coding genes lost in individuals with Prader-Willi syndrome (PWS), a sporadic chromosome deletion disorder characterized by hypothalamic dysfunction with hyperphagia and severe obesity [57]. Necdin and MAGEL2, which are part of a multiprotein family related by a MAGE homology domain, are expressed in hypothalamic areas, such as the ARC and PVN, that are involved in the regulation of energy balance $[58,59]$. Lee et al. [60] have recently found that necdin physically interacts with components of the centrosomes, which play a role in organizing microtubules during axonal outgrowth. As it might be expected from this observation, axons from necdin-null neurons elongate more slowly and are less bundled when grown in culture and several axonal tracts are reduced or misrouted in the brain of necdin-null embryos [60]. These interesting observations raise the possibility that the hypothalamic dysfunction of PWS patients is caused by abnormal axonal connections. Hypothalamic axonal defects were not described in these mice, possibly because these projections do not form easily detectable bundles. Their visualization requires specific labeling, the use of which has not yet been reported. Another possibility is that MAGEL2 plays a similar role during development and that disruption of hypothalamus connections are observed only when both necdin and MAGEL2 expression is lost, explaining the lack of single mutations in PWS. Of note, necdin physically interacts with BBS4, one of the several genes mutated in BardetBiedl syndrome, raising the possibility that similar axonal defects exist in this condition also characterized by early onset obesity [60]. Finally, a decrease of OT and GnRH cells has been observed in hypothalamus of Necdin-mutant mice, also possibly contributing to PWS phenotype [61].

Although loss of these genes individually does not have a dramatic effect on hypothalamic development, it is pos- 
sible that the combined loss of several genes that are only expressed from the paternal allele, as found in parthenogenetic cells, could have more severe consequences, explaining the absence of these cells in chimeric hypothalamus late during development. Why then are imprinted genes required for hypothalamus development? One theory interprets imprinting as a tug-of-war between the interests of each parent through their genome [62]. Paternally derived alleles would enhance the offspring's own fitness, favoring greater maternal investment whether or not this investment occurs before or after weaning. In the context of this theory, building a functional hypothalamus would allow optimal growth and survival of offspring, which is to the advantage of the father.

\section{Conclusion}

The study of hypothalamus development can foster insight into critical physiological processes and their disorders, as it has been shown for other regulatory centers of homeostasis such as the pituitary and pancreas $[63,64]$.
First, pathways that control differentiation, especially at the later stages, can be maintained in mature cells for the regulation of physiological effectors, like hormones or neurotransmitters, representing critical targets for therapies. Second, subtle developmental defects affecting the number of hypothalamic cells, their differentiation, or their axonal projections have the potential of causing metabolic and physiological disorders which can be isolated and expressed relatively late in life. As discussed in this review, instances of developmental defects of the hypothalamus affecting energy balance have been reported. We predict that disruption of hypothalamic development can also cause other phenotypes, such as high blood pressure or abnormal responses to stress, that are not as readily detectable as dysregulation of energy balance in animal models. Given that small groups of hypothalamic neurons like the PNV or ARC can participate in the regulation of multiple homeostatic processes, we would also predict that disruption of a single developmental pathway could generate several phenotypes that may coexist in an animal model or in a patient.

\section{References}

1 Wray S: Development of gonadotropin-releasing hormone-1 neurons. Front Neuroendocrinol 2002; 23:292-316.

$\checkmark 2$ Wilson SW, Houart C: Early steps in the development of the forebrain. Dev Cell 2004;6:167_ 181.

\3 Roessler E, Muenke M: How a hedgehog might see holoprosencephaly. Hum Mol Genet 2003; 12:R15-R25.

4 Ming JE, Muenke M: Multiple hits during early embryonic development: digenic diseases and holoprosencephaly. Am J Hum Genet 2002;71:1017-1032.

$\checkmark 5$ Ohkubo Y, Chiang C, Rubenstein JL: Coordinate regulation and synergistic actions of BMP4 SHH and FGF8 in the rostral prosencephalon regulate morphogenesis of the telencephalic and optic vesicles. Neuroscience 2002;111:1-17.

-6 Kapsimali M, Caneparo L, Houart C, Wilson SW: Inhibition of Wnt/Axin/beta-catenin pathway activity promotes ventral CNS midline tissue to adopt hypothalamic rather than floorplate identity. Development 2004;131: 5923-5933.

7 Daikoku S, Chikamori M, Adachi T, Okamura Y, Nishiyama T, Tsuruo Y: Ontogenesis of hypothalamic immunoreactive ACTH cells in vivo and in vitro: role of Rathke's pouch. Dev Biol 1983;97:81-88.
8 Hermesz E, Williams-Simons L, Mahon KA: A novel inducible element activated by contact with Rathke's pouch is present in the regulatory region of the Rpx/Hesx 1 homeobox gene. Dev Biol 2003;260:68-78.

-9 Michaud JL, Rosenquist T, May NR, Fan CM: Development of neuroendocrine lineages requires the BHLH-PAS transcription factor SIM1. Genes Dev 1998;12:3264-3275.

10 Michaud JL, DeRossi C, May NR, Holdener BC, Fan CM: ARNT2 acts as the dimerization partner of SIM1 for the development of the hypothalamus. Mech Dev 2000;90:253-261.

11 Hosoya T, Oda Y, Takahashi S, Morita M, Kawauchi S, Ema M, Yamamoto M, FujiiKuriyama Y: Defective development of secretory neurones in the hypothalamus of Arnt2knockout mice. Genes Cells 2001;6:361-374.

12 Keith B, Adelman DM, Simon MC: Targeted mutation of the murine arylhydrocarbon receptor nuclear translocator 2 (Arnt2) gene reveals partial redundancy with Arnt. Proc Natl Acad Sci USA 2001;98:6692-6697.

$\checkmark 13$ Acampora D, Postiglione MP, Avantaggiato V, Di Bonito M, Vaccarino FM: Michaud J, Simeone A: Progressive impairment of developing neuroendocrine cell lineages in the hypothalamus of mice lacking the Orthopedia gene. Genes Dev 1999;13:2787-2800.
14 Wang W, Lufkin T: The murine Otp homeobox gene plays an essential role in the specification of neuronal cell lineages in the developing hypothalamus. Dev Biol 2000;227:432-449.

-15 Schonemann MD, Ryan AK, McEvilly RJ, O'Connell CA: Development and survival of the endocrine hypothalamus and posterior pituitary gland requires the neuronal POU domain factor BRN2. Genes Dev 1995;9:31223135.

16 Nakai S, Kawano H, Yudate T, Nishi M, Kuno J, Nagata A, Jishage K, Hamada H, Fujii H, Kawamura K: The POU domain transcription factor Brn-2 is required for the determination of specific neuronal lineages in the hypothalamus of the mouse. Genes Dev 1995;9:3109_ 3121 .

17 Goshu E, Jin H, Lovejoy J, Marion JF, Michaud JL, Fan CM: Sim 2 contributes to neuroendocrine hormone gene expression in the anterior hypothalamus. Mol Endocrinol 2004; 18 : 1251-1262.

18 Dickson SL, Luckman SM: Induction of c-fos messenger ribonucleic acid in neuropeptide $\mathrm{Y}$ and growth hormone $(\mathrm{GH})$-releasing factor neurons in the rat arcuate nucleus following systemic injection of the $\mathrm{GH}$ secretagogue $\mathrm{GH}$ releasing peptide-6. Endocrinology 1997;138: 771-777. 
19 Kimura S, Hara Y, Pineau T, Fernandez-Salguero P, Fox CH, Ward JM, Gonzalez FJ: The T/Ebp null mouse: thyroid-specific enhancerbinding protein is essential for the organogenesis of the thyroid lung ventral forebrain and pituitary. Genes Dev 1996;10:60-69.

-20 Ericson J, Muhr J, Placzek M, Lints T, Jessell TM, Edlund T: Sonic hedgehog induces the differentiation of ventral forebrain neurons: a common signal for ventral patterning within the neural tube. Cell 1995;81:747-756.

-21 Pabst O, Herbrand H, Takuma N, Arnold HH: NKX2 gene expression in neuroectoderm but not in mesendodermally derived structures depends on Sonic Hedgehog in mouse embryos. Dev Genes Evol 2000;210:47-50.

\22 Marin O, Baker J, Puelles L, Rubenstein JL: Patterning of the basal telencephalon and hypothalamus is essential for guidance of cortical projections. Development 2002;129:761773.

-23 Li H, Zeitler PS, Valerius MT, Small K, Potter SS: Gsh-1 an orphan Hox gene is required for normal pituitary development. EMBO J 1996; 15:714-724.

-24 Wang W, Grimmer JF, Van De Water TR, Lufkin T: Hmx2 and Hmx3 homeobox genes direct development of the murine inner ear and hypothalamus and can be functionally replaced by Drosophila Hmx. Dev Cell 2004; 7: 439-453.

-25 Shinoda K, Lei H, Yoshii H, Nomura M, Nagano M, Shiba H, Sasaki H, Osawa Y, Ninomiya Y, Niwa O: Developmental defects of the ventromedial hypothalamic nucleus and pituitary gonadotroph in the Ftz-F1 disrupted mice. Dev Dyn 1995;204:22-29.

$\checkmark 26$ Ingraham HA, Lala DS, Ikeda Y, Luo X, Shen WH, Nachtigal MW, Abbud R, Nilson JH, Parker KL: The nuclear receptor steroidogenic factor 1 acts at multiple levels of the reproductive axis. Genes Dev 1994; 8:2302-2312.

$\checkmark 27$ Dellovade TL, Young M, Ross EP, Henderson R, Caron K, Parker K, Tobet SA: Disruption of the gene encoding SF-1 alters the distribution of hypothalamic neuronal phenotypes. J Comp Neurol 2000;423:579-589.

-28 Ikeda Y, Luo X, Abbud R, Nilson JH, Parker KL: The nuclear receptor steroidogenic factor 1 is essential for the formation of the ventromedial hypothalamic nucleus. Mol Endocrinol 1995;9:478-486.

29 Majdic G, Young M, Gomez-Sanchez E, Anderson P, Szczepaniak LS, Dobbins RL, McGarry JD, Parker KL: Knockout mice lacking steroidogenic factor 1 are a novel genetic model of hypothalamic obesity. Endocrinology 2002; 143:607-614.

-30 Tran PV, Lee MB, Marin O, Xu B, Jones KR, Reichardt LF, Rubenstein JR, Ingraham HA: Requirement of the orphan nuclear receptor SF-1 in terminal differentiation of ventromedial hypothalamic neurons. Mol Cell Neurosci 2003;22:441-453.
31 Davis AM, Seney ML, Stallings NR, Zhao L, Parker KL, Tobet SA: Loss of steroidogenic factor 1 alters cellular topography in the mouse ventromedial nucleus of the hypothalamus. J Neurobiol 2004;60:424-436.

32 Michaud JL, Boucher F, Melnyk A, Gauthier F, Goshu E, Levy E, Mitchell GA, Himms-Hagen J, Fan CM: Sim 1 haploinsufficiency causes hyperphagia obesity and reduction of the paraventricular nucleus of the hypothalamus. Hum Mol Genet 2001;10:1465-1473.

33 Holder JL Jr, Zhang L, Kublaoui BM, DiLeone RJ, Oz OK, Bair CH, Lee YH, Zinn AR: Sim 1 gene dosage modulates the homeostatic feeding response to increased dietary fat in mice. Am J Physiol Endocrinol Metab 2004;287: E105-E113.

34 Holder JL Jr, Butte NF, Zinn AR: Profound obesity associated with a balanced translocation that disrupts the SIM1 gene. Hum Mol Genet 2000;9:101-108.

35 Villa A, Urioste M, Bofarull JM, MartinezFrias ML: De novo interstitial deletion Q16.2q21 on chromosome 6. Am J Med Genet 1995;55:379-383.

36 Turleau C, Demay G, Cabanis MO, Lenoir G, de Grouchy J: 6q1 monosomy: a distinctive syndrome. Clin Genet 1988;34:38-42.

37 Gilhuis HJ, van Ravenswaaij CM, Hamel BJ, Gabreels FJ: Interstitial 6q deletion with a Prader-Willi-like phenotype: a new case and review of the literature. Eur J Paediatr Neurol 2000;4:39-43.

38 Meyre D, Lecoeur C, Delplanque J, Francke S, Vatin V, Durand E, Weill J, Dina C, Froguel P: A genome-wide scan for childhood obesityassociated traits in French families shows significant linkage on chromosome 6q22.31Q23.2. Diabetes 2004;53:803-811.

39 Wong LF, Murphy D: Adenoviral-mediated over-expression of Brn 2 in the rat paraventricular nucleus: no effect on vasopressin or corticotrophin releasing factor RNA levels. Mol Cell Endocrinol 2003;200:165-175.

40 Kovacs KJ, Sawchenko PE: Sequence of stressinduced alterations in indices of synaptic and transcriptional activation in parvocellular neurosecretory neurons. J Neurosci 1996; 16:262273.

41 Ramkumar T, Adler SA: Requirement for the POU transcription factor Brn-2 in corticotropin-releasing hormone expression in a neuronal cell line. Mol Endocrinol 1999;13:12371248.

42 Rogers MC, Silverman AJ, Gibson MJ: Gonadotropin-releasing hormone axons target the median eminence: in vitro evidence for diffusible chemoattractive signals from the mediobasal hypothalamus. Endocrinology 1997;138: 3956-3966.

43 Deiner MS, Sretavan DW: Altered midline axon pathways and ectopic neurons in the developing hypothalamus of netrin-1- and DCCdeficient mice. J Neurosci 1999; 19:99009912.

44 Markakis EA: Development of the neuroendocrine hypothalamus. Front Neuroendocrinol 2002;23:257-291.
45 Bouret SG, Draper SJ, Simerly RB: Formation of projection pathways from the arcuate nucleus of the hypothalamus to hypothalamic regions implicated in the neural control of feeding behavior in mice. J Neurosci 2004;24: 2797-2805.

46 Proulx K, Richard D, Walker CD: Leptin regulates appetite-related neuropeptides in the hypothalamus of developing rats without affecting food intake. Endocrinology 2002; 143: 4683-4692.

47 Bouret SG, Draper SJ, Simerly RB: Trophic action of leptin on hypothalamic neurons that regulate feeding. Science 2004;304:108-110.

48 Gluckman PD: Maturation of hypothalamicpituitary function in the ovine fetus and neonate. Ciba Found Symp 1981;86:5-42.

49 Clancy B, Darlington RB, Finlay BL: Translating developmental time across mammalian species. Neuroscience 2001;105:7-17.

50 Avishai-Eliner S, Brunson KL, Sandman CA, Baram TZ: Stressed-out or in (utero)? Trends Neurosci 2002;25:518-524.

51 Rinaman L: Postnatal development of hypothalamic inputs to the dorsal vagal complex in rats. Physiol Behav 2003;79:65-70.

52 Blevins JE, Schwartz MW, Baskin DG: Evidence that paraventricular nucleus oxytocin neurons link hypothalamic leptin action to caudal brain stem nuclei controlling meal size. Am J Physiol Regul Integr Comp Physiol 2004; 287:R87-R96.

53 Rinaman L, Vollmer RR, Karam J, Phillips D, Li X, Amico JA: Dehydration anorexia is attenuated in oxytocin-deficient mice. Am J Physiol Regul Integr Comp Physiol 2005;288: R1791-R1799.

54 Allen ND, Logan K, Lally G, Drage DJ, Norris ML, Keverne EB: Distribution of parthenogenetic cells in the mouse brain and their influence on brain development and behavior. Proc Natl Acad Sci USA 1995;92:10782-10786.

55 Keverne EB, Fundele R, Narasimha M, Barton SC, Surani MA: Genomic imprinting and the differential roles of parental genomes in brain development. Brain Res Dev Brain Res 1996; 92:91-100.

56 Curley JP, Pinnock SB, Dickson SL, Thresher R, Miyoshi N, Surani MA, Keverne EB: Increased body fat in mice with a targeted mutation of the paternally expressed imprinted gene Peg3. FASEB J2005; 19:1302-1304.

57 Goldstone AP: Prader-Willi syndrome: advances in genetic pathophysiology and treatment. Trends Endocrinol Metab 2004;15:1220.

58 Andrieu D, Watrin F, Niinobe M, Yoshikawa K, Muscatelli F, Fernandez PA: Expression of the Prader-Willi gene necdin during mouse nervous system development correlates with neuronal differentiation and P75NTR expression. Gene Expr Patterns 2003;3:761-765.

59 Lee S, Walker CL, Wevrick R: Prader-Willi syndrome transcripts are expressed in phenotypically significant regions of the developing mouse brain. Gene Expr Patterns 2003;3:599609 
60 Lee S, Walker CL, Karten B, Kuny SL, Tennese AA, O'Neill MA, Wevrick R: Essential role for the Prader-Willi syndrome protein necdin in axonal outgrowth. Hum Mol Genet 2005; 14 : $627-637$.

-61 Jay P, Rougeulle C, Massacrier A, Moncla A, Mattei MG, Malzac P, Roeckel N, Taviaux S, Lefranc JL, Cau P, Berta P, Lalande M, Muscatelli F: The human necdin gene NDN is maternally imprinted and located in the PraderWilli syndrome chromosomal region. Nat Genet 1997; 17:357-361.

-62 Haig D: Genomic imprinting and kinship: how good Is the evidence? Annu Rev Genet 2004; 38:553-585.

63 Pulichino AM, Vallette-Kasic S, Couture C, Gauthier Y, Brue T, David M, Malpuech G, Deal C, Van Vliet G, De Vroede M, Riepe FG, Partsch CJ, Sippell WG, Berberoglu M, Atasay B, Drouin J: Human and mouse TPIT gene mutations cause early onset pituitary ACTH deficiency. Genes Dev 2003;17:711-716.
64 Habener JF, Kemp DM, Thomas MK: Minireview: transcriptional regulation in pancreatic development. Endocrinology 2005;146: 1025-1034.

-65 Elmquist JK, Elias CF, Saper CB: From lesions to leptin: hypothalamic control of food intake and body weight. Neuron 1999;22:221-232.

66 Elias CF, Aschkenasi C, Lee C, Kelly J, Ahima RS, Bjorbaek C, Flier JS, Saper CB, Elmquist JK: Leptin differentially regulated NPY and POMC neurons projecting to the lateral hypothalamic area. Neuron 1999;23:775-786.

67 Cowley MA, Pronchuk N, Fan W, Dinulescu DM, Colmers WF, Cone RD: Integration of NPY AGRP and melanocortin signals in the hypothalamic paraventricular nucleus: evidence of a cellular basis for the adipostat. Neuron 1999;24:155-163.

68 Billington CJ, Briggs JE, Grace M, Levine AS: Effects of intracerebroventricular injection of neuropeptide Y on energy metabolism. Am J Physiol 1991;260:R321-R327.
69 Graham M, Shutter JR, Sarmiento V, Sarosi I, Stark KL: Over-expression of Agrt leads to obesity in transgenic mice. Nat Genet 1997;17: 273-274.

70 Ollmann MM, Wilson BD, Yang YK, Kerns JA, Chen Y, Gantz I, Barsln GS: Antagonism of central melanocortin receptors in vitro and in vivo by Agouti-related protein. Science 1997;278:135-138.

71 Fan W, Boston BA, Kesterson RA, Hruby VJ, Cone RD: Role of melanocortinergic neurons in feeding and the agouti obesity syndrome. Nature 1997;385:165-168.

72 Kristensen P, Judge ME, Thim L, Ribel U, Christjansen KN, Wulff BS, Clausen JT, Jensen PB, Madsen OD, Vrang N, Larsen PJ, Hastrup S: Hypothalamic CART is a new anorectic peptide regulated by leptin. Nature 1998;393: $72-76$. 